\title{
Assessing the Molecular Diversity in Groundnut (Arachis hypogaea L.) Genotypes Using Microsatellite-Based Markers
}

\author{
Hasanali Nadaf $^{1 *}$, G. Chandrashekhara, B.N. Harish Babu ${ }^{1}$ and D.L. Savithramma ${ }^{1,2}$ \\ ${ }^{1}$ Department of Genetics and Plant Breeding, University of Agricultural and \\ Horticultural Sciences Shivamogga, India \\ ${ }^{2}$ Department of Genetics and Plant Breediing, University of Agricultural Sciences \\ Bengaluru, India
}

*Corresponding author

\section{A B S T R A C T}

\section{Keywords}

Groundnut, DNA extraction, PCR amplification, molecular diversity, $\mathrm{SSR}_{\mathrm{s}}$, dendrogram, polymorphic information content, Jaccard's similarity coefficient

\section{Article Info}

Accepted:

15 August 2019

Available Online:

10 September 2019
Groundnut (Arachis hypogaea L.) production is constrained by a myriad of biotic and abiotic stresses which necessitate the development and use of superior varieties for increased yield. Germplasm characterisation both at the phenotypic and molecular level becomes important in all plant breeding programs. The aim of this study was to characterise groundnut genotypes at molecular level using simple sequence repeats (SSR). A total of 30 SSR markers were screened and 20 were found to be polymorphic with an average polymorphic information content (PIC) value of 0.57 . Of the 66 groundnut genotypes studied, $57 \%$ showed very close relationship ( $~ 80 \%$ similarity) with one or more genotypes among themselves. The remaining $43 \%$ of the groundnut genotypes were distant from each other and could therefore serve as effective parental material for future work. In this study, the SSRs were found to be quite discriminatory in discerning variations between and among groundnut genotypes even where the level of variation was low. Microsatellite based markers therefore represent a useful tool for dissecting genetic variations in most of the cultivated crops, especially in groundnut.

\section{Introduction}

Application of molecular markers in plant breeding has established the need for information on varieties in DNA sequence even in those crops where little genetic and cytogenetic information is available; DNA markers provide a reliable means of estimating the genetic relationship between genotypes compared to morphological markers (Gepts,
1993). But, their application in groundnut enhancement is lagging behind because of limited knowledge of its genome.

Subrahmanyam et al. (2000) selected 70 genotypes exhibiting variation for several morphological, physiological and other characters and studied polymorphism using random amplified polymorphic DNA (RAPD) assay wherein only seven out of 48 
oligonucleotide primers were polymorphic. Out of total 408 bands, 27 (6.6\%) bands were polymorphic. Dwivedi et al. (2001) selected 26 accessions and 8 primers for random amplified polymorphic DNA assay to determine genetic diversity. The genetic similarity (Sij) was ranged from 59.0 to 98.8 per cent with an average of 86.2 per cent. Both multidimensional scaling and unweighted pair group method with arithmetic averages (UPGMA) dendrogram revealed the existence of five distinct clusters. Some accessions with diverse DNA profile (ICG 1448, 7101, 1471, 99106 and 99014) were identified for mapping and genetic enhancement in groundnut. Raina et al. (2001) used 71 random and 29 SSR primers to assess genetic variation and interrelationships among sub-species and botanical varieties of cultivated groundnut. They reported that 42.7 and 54.4 per cent polymorphism from RAPD and SSR primers, respectively. Also the dendrogram based on RAPD, ISSR and RAPD + ISSR data precisely organized the five botanical varieties of two sub-species into five clusters and established phylogenetic relationships among cultivated groundnut and Arachis wild species. Sohaib Roomi et al. (2014) studied molecular diversity of seventy accessions of Arachis hypogaea using 30 SSRs. Fifteen out of thirty primers generated polymorphic bands. The number of polymorphic loci detected was ranged from 2 to 4 per primer, with an average of 2.6 loci per primer. All accessions were then divided into six clusters at 0.67 coefficient of similarity. Xiaoping Ren et al. (2014) evaluated 196 peanut (Arachis hypogaea L.) cultivars of China using one hundred and forty-six polymorphic simple sequence repeat (SSR) markers, which amplified 440 polymorphic bands with an average of 2.99, and the average gene diversity index was 0.11. A model-based population structure analysis divided these peanut cultivars into five subpopulations (P1a, P1b, P2, P3a and P3b).
For molecular characterization of 48 selected groundnut advanced breeding lines with different phenotypic attributes, Frimpong et al., (2015) used 53 simple sequence repeats (SSR) markers. Out of 53 SSR markers screened, 25 were found to be polymorphic among selected lines with average polymorphic information content (PIC) of 0.57 and about 33 per cent of the groundnut genotypes were distant from each other and therefore can serve as effective parental material for future breeding work.

\section{Materials and Methods}

A total of 66 groundnut genotypes were used for the molecular diversity analysis using 30 $\mathrm{SSR}_{\mathrm{s}}$, DNA isolation of genotypes was carried out using modified CTAB method as described below.

Two grams of fresh leaf sample (18-25 days) was crushed in liquid nitrogen with a pinch of PVP, then $500 \mu \mathrm{l}$ of CTAB extraction buffer was added and crushed finely, extract was transferred to $2 \mathrm{ml}$ eppendorf tube. Later 500 $\mu l$ of $\mathrm{CTAB}$ extraction buffer was added to mortar. Now all the leftover extract was poured into the eppendorf tube, $2-3 \mu$ of mercaptoethnol was added to each tube and vortexed for better mixing. The mixture was kept in water bath at $65-70{ }^{\circ} \mathrm{C}$ for $45-60 \mathrm{~min}$. Mixture was centrifuged at $12000 \mathrm{rpm}$ for 15$18 \mathrm{~min}$; then slowly the supernatant was pipetted out into another $2 \mathrm{ml}$ eppendorf tube and add 500-600 $\mu \mathrm{l}$ of chloform : isoamylalcohol (24:1) and shaken well; mixture was centrifuged at $12000 \mathrm{rpm}$ for 20 min. The supernatant was pipetted out to another $2 \mathrm{ml}$ eppendorf tube and $500 \mu \mathrm{l}$ of freshly prepared phenol: chloroform: isoamylalcohol (25:24:1) was added and mixed thoroughly; then mixture was again centrifuged at $12000 \mathrm{rpm}$ for $20 \mathrm{~min}$. Aqueous upper layer was pipetted out to a $1.5 \mathrm{ml}$ eppendorf tube, to this $500-600 \mu$ of chilled 
isopropanol was added and kept for overnight at $-20^{\circ} \mathrm{C}$. Next day tubes were shaken well and centrifuged at $14000 \mathrm{rpm}$ for $20-25 \mathrm{~min}$. A pellet formation at the bottom of tube was noticed and the supernatant was discarded; the pellets were added with $50-100 \mu$ of $70 \%$ ethanol (freshly prepared) and centrifuged at $12000 \mathrm{rpm}$ for $10-15 \mathrm{~min}$ for washing step. Afterwards ethanol was decanted off and pellets were kept for drying for 4-5 hr. After drying, 30-50 $\mu$ l of $1 \mathrm{x}$ TE buffer was added by looking at the size of the pellet and stored at $20^{\circ} \mathrm{C}$ (Hostington et al., 1997).

\section{Polymerase chain reaction was carried out as follows}

Requirements for polymerase chain reaction

SSR primers: A total of 30 SSR primers (Table 1) used for the present investigation were synthesized by a private firm. The basis for selection of these SSR primers was that, they have shown association with foliar disease resistance, tolerance to aflatoxin contamination and effectively deciphered molecular diversity in groundnut crop as cited by different groundnut researchers in the last one decade.

dNTPs: The four dNTPs viz., dATP, dCTP, dGTP and dTTP were obtained from private firm.

Taq DNA polymerase: Taq DNA polymerase and 10x Taq assay buffer were obtained from private firm.

\section{Preparation of master mix for PCR}

Master-mix was prepared by mixing different components in the proportion as shown below, and master mix was distributed to each tube ( $9 \mu \mathrm{l} /$ tube) and $1 \mu \mathrm{l}$ of template DNA from each genotype was added to make the final volume

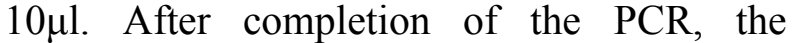
products were stored at $-40^{\circ} \mathrm{C}$ until the gelelectrophoresis was done.

Components of PCR master mix as given below:

\begin{tabular}{|c|l|c|}
\hline SI. No & Components & $\begin{array}{c}\text { Quantity } \\
(\boldsymbol{\mu l} / \text { tube })\end{array}$ \\
\hline 1 & 10x Assay buffer & 2 \\
\hline 2 & dNTPs $(2 \mathrm{mM})$ & 1 \\
\hline 3 & Primer $(5 \mathrm{pM})$ & 2 \\
\hline 4 & Taq DNA Polymerase & 0.33 \\
\hline 5 & Nano-pure water & 3.67 \\
\hline 6 & DNA template & 1 \\
\hline & Total & $\mathbf{1 0}$ \\
\hline
\end{tabular}

Steps followed in PCR reaction are described as follows:

\begin{tabular}{|c|l|c|c|c|}
\hline SI. No & \multicolumn{1}{|c|}{ Step } & \multicolumn{2}{|c|}{$\begin{array}{l}\text { Temperature } \\
\left({ }^{\circ} \mathbf{C}\right)\end{array}$} & \multicolumn{2}{|c|}{$\begin{array}{l}\text { Duration/cycle } \\
(\mathbf{m i n})\end{array}$} & $\begin{array}{c}\text { No. of } \\
\text { cycles }\end{array}$ \\
\hline $\mathbf{1}$ & Denaturation & 94 & 2 & 1 \\
\hline $\mathbf{2}$ & Annealing & $45-65$ & 2 & 30 \\
\hline $\mathbf{3}$ & Primer extension & 72 & 3 & \\
\hline $\mathbf{4}$ & Final extension & 72 & 10 & 1 \\
\hline
\end{tabular}


Gel-electrophoresis was conducted using Metaphor-agarose for fine separation of PCR products procedure followed is described below.

Metaphor-agarose was used for the separation of amplified PCR products of high resolution separation of $20 \mathrm{bp}-800 \mathrm{bp}$ DNA fragments. It can be best used for recovering fragments upto $800 \mathrm{bp}$. The PCR product was mixed with 2 $\mu l$ of loading dye (Bromphenol blue) and was loaded in 4 per cent metaphor agarose gel of 0.5x TAE buffer containing Ethidium bromide $(10 \mathrm{l} / 100 \mathrm{ml})$. Gel was run at 90 volts for $3 \mathrm{hr}$. The banding pattern in the gel was captured by using gel documentation system (Uvitech, Cambridge, England).

The amplified fragments were scored as ' 1 ' for presence and ' 0 ' for the absence of a band to generate a binary matrix. Similarity coefficients were calculated. A dendrogram was constructed based on similarity coefficient values using clustering technique of unweighted pair group arithmetic mean (UPGMA) using SHAN module of NTSYSpc version 2.0 (Rohlf, 1998).

\section{Results and Discussion}

Totally thirty SSR markers were used to assess the diversity among the genotypes under study. Out of 30 SSRs, twenty were polymorphic and remaining 10 were monomorphic (Table 2). The polymorphism percentage for primers ranged from zero (S70) to 100 per cent (GM-1986) with an overall average of 74.32 per cent. Number of amplified fragments ranged from 1 to 6 in a given SSR primer. On an average 3.15 bands per primer were amplified. Ten SSR primers viz., GM-1864, pPGPseq-2F05, GM-1502, GM-2084, GM-2348, S-03, S-83, S-21, S-70 and pPGSseq19D9 showed monomorphic bands in all genotypes. The PIC (polymorphic information content) values were calculated to identify most polymorphic primer and it ranged from 0 (GM 1864) to 0.83 (GM-1986) with mean PIC of 0.57 per primer. The SSR primer, GM-1986 (0.83) has shown highest PIC value followed by GM-1991 (0.77) and PM 35 (0.75).

To assess the diversity among the 66 groundnut genotypes Jaccard's similarity coefficient was calculated using NTSYSpc v. 2.2 and a dendrogram was generated based on the unweighted pair-group method with arithmetic mean (UPGMA) procedure (Figure 1). The mean similarity indices for 66 genotypes was 0.76 with a range 0.37 to 0.98 indicating that accessions had 76 per cent of their SSR alleles in common. The genotypes ICGV-15143 and Dh-101 were most diverse in comparison with other genotypes.

The dendrogram revealed 16 distinct clusters at similarity coefficient of 0.78 . Cluster-

II (38) has highest number of genotypes followed by cluster-III (7), cluster-I (5), cluster IV

(3) and cluster XIV (2) remaining eleven clusters were found solitary in nature. Genotype TMV-2 has similarity coefficient of 0.70 and 0.77 with J-11 and JL-24, respectively.

Twenty out of the 30 SSR markers (66.67\%) successfully amplified polymorphic fragments in all the 66 groundnut genotypes tested. The SSR markers have amplified a total of 74 alleles with an average of 3.15 alleles per marker. A number of reports on the use of SSR markers to characterise groundnut have produced results similar to those obtained in this study. For example, Mace et al., (2006), who used 23 SSR primers to study 22 groundnut genotypes with varying levels of resistance to rust and early leaf spot, recorded $52 \%$ polymorphism. 
Table.1 Description of the SSR primers used in the experiment

\begin{tabular}{|c|c|c|c|c|c|}
\hline SI.No & Primer name & Sequence & No. of base pairs & Reported in groundnut as & Reference \\
\hline \multirow[t]{2}{*}{1} & pPGSseq19D9 & F: TGTTGCCCACTGTTCTAATCA & 21 & \multirow{2}{*}{ Linked to aflatoxin tolerance } & \multirow[t]{2}{*}{ Hong et al., (2009) } \\
\hline & & R: TCAAATGGCATAGTCTCCCC & 20 & & \\
\hline \multirow[t]{2}{*}{2} & \multirow{2}{*}{ GM1954 } & F: GAGGAGTGTGAGGTTCTGACG & 22 & \multirow{2}{*}{ Linked to rust resistance } & \multirow{2}{*}{ Yol et al.,(2016) } \\
\hline & & R: TGGTTCATTGCATTTGCATAC & 21 & & \\
\hline \multirow[t]{2}{*}{3} & \multirow[t]{2}{*}{ GM1911 } & F: CAGCTTTCTTTCAATTCATCCA & 22 & \multirow[t]{2}{*}{ Linked to early leaf spot resistance } & \multirow[t]{2}{*}{ Zongo et al.,(2017) } \\
\hline & & R: CACTTCGTGTTCTTCCTGCTC & 21 & & \\
\hline \multirow[t]{2}{*}{4} & \multirow[t]{2}{*}{ GM1883 } & F: АСССТТСТТСТССАСАТССАС & 21 & \multirow[t]{2}{*}{ Linked to early leaf spot resistance } & \multirow[t]{2}{*}{ Zongo et al.,(2017) } \\
\hline & & R: GGTTTGGGGCTTAACAGAGAC & 22 & & \\
\hline \multirow[t]{2}{*}{5} & \multirow[t]{2}{*}{ GM1000 } & F: CAGCCCCTTTCTTTTAATCCA & 21 & \multirow[t]{2}{*}{ Linked to early leaf spot resistance } & \multirow[t]{2}{*}{ Zongo et al.,(2017) } \\
\hline & & R: CATTATGAGGGAAGCCAGACA & 21 & & \\
\hline \multirow[t]{2}{*}{6} & \multirow[t]{2}{*}{ PM 50} & F: CAATTCATGATAGTATTTTATTGGACA & 27 & \multirow[t]{2}{*}{ Linked to rust resistance } & \multirow{2}{*}{$\begin{array}{l}\text { Mondal and Badigannavar } \\
\text { (2010) }\end{array}$} \\
\hline & & R: CTTTCTCCTCCCCAATTTGA & 20 & & \\
\hline \multirow[t]{2}{*}{7} & \multirow[t]{2}{*}{ PM 179} & F: CTGATGCATGTTTAGCACACTT & 22 & \multirow[t]{2}{*}{ Linked to rust resistance } & \multirow{2}{*}{$\begin{array}{l}\text { Mondal and Badigannavar } \\
\text { (2010) }\end{array}$} \\
\hline & & R: TGAGTTGTGACGGCTTGTGT & 20 & & \\
\hline \multirow[t]{2}{*}{8} & \multirow[t]{2}{*}{ PM 35} & F: TGTGAAACCAAATCACTTTCATTC & 24 & \multirow{2}{*}{ Linked to rust resistance } & \\
\hline & & R: TGGTGAAAAGAAAGGGGAAA & 20 & & (2010) \\
\hline 9 & pPGPseq-2B10 & F: AATGCATGAGCTTCCATCAA & 20 & Linked to late leaf spot resistance & Mace et al.,(2006) \\
\hline & & R: AACCCCATCTTAAAATCTTACCAA & 24 & & \\
\hline 10 & pPGPseq-2F05 & F: TGACCAAAGTGATGAAGGGA & 20 & Linked to late leaf spot and rust & Mace et al.,(2006) \\
\hline & & R: AAGTTGTTTGTACATCTGTCATCG & 24 & resistance & \\
\hline 11 & GM 1502 & F: TTCCTTTACACACACGCACAC & 21 & Molecular diversity studies & Frimpong et al. (2015) \\
\hline & & R: TGGAGGAAATGTAGGGAAAGG & 21 & & \\
\hline 12 & S 84 & F: CAGCCAATATGTCACAACCCTAAT & 24 & Molecular diversity studies & Frimpong et al. (2015) \\
\hline & & R: CTCCCACTACAAATCTCCAATCAAT & 25 & & \\
\hline 13 & GM 2637 & F: ATGCTCTCAGTTCTTGCCTGA & 21 & Molecular diversity studies & Frimpong et al. (2015) \\
\hline & & R: AAGGAGCCAGCTAGCTACATAGT & 23 & & \\
\hline 14 & GM 1577 & F: GCGGTGTTGAAGTTGAAGAAG & 21 & Molecular diversity studies & Frimpong et al. (2015) \\
\hline & & R: TAACGCATTAACCACACACCA & 21 & & \\
\hline 15 & GM 1937 & F: TTCATCCTCTGCTTCCTTTGA & 21 & Molecular diversity studies & Frimpong et al. (2015) \\
\hline & & R: TGACCAAACCCATCATCATCT & 21 & & \\
\hline 16 & GM 1986 & F: GCTGCTGCAAGTCTTAAGGAA & 21 & Molecular diversity studies & Frimpong et al. (2015) \\
\hline & & R: AAAGTGTCAGGTGCAAAGCAT & 21 & & \\
\hline
\end{tabular}


Continued............

\begin{tabular}{|c|c|c|c|c|c|}
\hline SI.No & Primer name & Sequence & No. of base pairs & Reported in groundnut as & Reference \\
\hline \multirow[t]{2}{*}{17} & \multirow{2}{*}{ GM 2084} & F: CGCAGAAATGAACCGAAATTA & 21 & \multirow{2}{*}{ Molecular diversity studies } & \multirow{2}{*}{ Frimpong et al. (2015) } \\
\hline & & R: GGATGCATTCTTCTTCCTCCT & 21 & & \\
\hline \multirow[t]{2}{*}{18} & \multirow[t]{2}{*}{ GM 1991} & F: GAAAATGATGCCGAGAAATGT & 21 & \multirow[t]{2}{*}{ Molecular diversity studies } & \multirow[t]{2}{*}{ Frimpong et al. (2015) } \\
\hline & & R: GGGGAGAGATGCAGAAAGAGA & 21 & & \\
\hline \multirow[t]{2}{*}{19} & \multirow[t]{2}{*}{ GM 2053} & F: ACAAGGAAAACCCATCCAATC & 21 & \multirow[t]{2}{*}{ Molecular diversity studies } & \multirow[t]{2}{*}{ Frimpong et al. (2015 } \\
\hline & & R: ACGTGATGGATTCTTGTGGAG & 21 & & \\
\hline \multirow[t]{2}{*}{20} & \multirow[t]{2}{*}{ GM 1834} & F: GAAGCAAGAAACCAACCAAGTC & 22 & \multirow[t]{2}{*}{ Molecular diversity studies } & \multirow[t]{2}{*}{ Frimpong et al. (2015) } \\
\hline & & R: GTGATAAAGCGGCCACAATAG & 21 & & \\
\hline \multirow[t]{2}{*}{21} & \multirow[t]{2}{*}{ S 93} & F: TTGGGGAAATACAGAATAACG & 21 & \multirow[t]{2}{*}{ Molecular diversity studies } & \multirow[t]{2}{*}{ Frimpong et al. (2015) } \\
\hline & & R: CTCCCACATCCCCACCAT & 18 & & \\
\hline \multirow[t]{2}{*}{22} & \multirow[t]{2}{*}{ GM 2348} & F: ACACAAGAACCACCAAAAGCA & 21 & \multirow[t]{2}{*}{ Molecular diversity studies } & \multirow[t]{2}{*}{ Frimpong et al. (2015) } \\
\hline & & R: CAGCGCCATTTCTCAACTATC & 21 & & \\
\hline \multirow[t]{2}{*}{23} & \multirow[t]{2}{*}{ S 03} & F: GCACCAATTTTGTCCCTGAT & 20 & \multirow[t]{2}{*}{ Molecular diversity studies } & \multirow[t]{2}{*}{ Frimpong et al. (2015) } \\
\hline & & R: AAGGGGTTTGCACGTAAATG & 20 & & \\
\hline \multirow[t]{2}{*}{24} & \multirow[t]{2}{*}{ S 83} & F: CTTGAACTTATTTTTGGTGGGTGAAC & 26 & \multirow[t]{2}{*}{ Molecular diversity studies } & \multirow[t]{2}{*}{ Frimpong et al. (2015) } \\
\hline & & R: CAAGGGAGAATGAAGAATGCTAAG & 24 & & \\
\hline 25 & S 23 & F: CTGGAAGTGGTCCTGTTGGT & 20 & Molecular diversity studies & Frimpong et al. (2015) \\
\hline & & R: GCTGCTCCTGTCTCTGGAAT & 20 & & \\
\hline 26 & S 21 & F: AGTCCTACTTGTGGGGGTTG & 20 & Molecular diversity studies & Frimpong et al. (2015) \\
\hline & & R: TCCCTTTTGCAGTGAAATCC & 20 & & \\
\hline 27 & S 70 & F: CCTTTCCCATTCCATTAGC & 19 & Molecular diversity studies & Frimpong et al. (2015) \\
\hline & & R: GTCCGAGTTGAGGAACAACAA & 21 & & \\
\hline 28 & S 80 & F: GGCGTCCCATTGCTTAC & 17 & Molecular diversity studies & Frimpong et al. (2015) \\
\hline & & R: AGAATGCGTTGATGTTATGAA & 21 & & \\
\hline 29 & GM 1864 & F: CAACACACCCAGTCACTCTCTC & 22 & Molecular diversity studies & Frimpong et al. (2015) \\
\hline & & R: TCCTTTCTGATGTTCTGTGTGTG & 23 & & \\
\hline 30 & GM 1959 & F: GTGTTCTCAGCCATCTTTTCG & 21 & Molecular diversity studies & Frimpong et al. (2015) \\
\hline & & R: GTGAAGGTGTTGTGAATGCAG & 21 & & \\
\hline
\end{tabular}

Note: F: Forward primer; R-Reverse primer 
Table.2 Polymorphism of markers used in the present investigation

\begin{tabular}{|c|c|c|c|c|}
\hline $\begin{array}{l}\text { Sl. } \\
\text { No. }\end{array}$ & Marker name & $\begin{array}{c}\text { Polymorphic } \\
\text { information content }\end{array}$ & $\begin{array}{c}\text { Polymorphism } \\
(\%)\end{array}$ & $\begin{array}{l}\text { No. of } \\
\text { Alleles }\end{array}$ \\
\hline 1 & GM 1986 & 0.83 & 100 & 6 \\
\hline 2 & GM 1991 & 0.77 & 100 & 6 \\
\hline 3 & PM 35 & 0.75 & 100 & 4 \\
\hline 4 & GM 1577 & 0.75 & 100 & 4 \\
\hline 5 & GM 2053 & 0.75 & 25 & 4 \\
\hline 6 & GM 1959 & 0.75 & 100 & 4 \\
\hline 7 & S 84 & 0.74 & 100 & 4 \\
\hline 8 & GM 1911 & 0.71 & 100 & 4 \\
\hline 9 & GM 2637 & 0.69 & 100 & 4 \\
\hline 10 & GM 1954 & 0.58 & 100 & 3 \\
\hline 11 & GM 1937 & 0.50 & 100 & 2 \\
\hline 12 & S 80 & 0.50 & 100 & 2 \\
\hline 13 & GM 1883 & 0.49 & 100 & 2 \\
\hline 14 & S 93 & 0.49 & 100 & 2 \\
\hline 15 & GM 1834 & 0.44 & 50 & 2 \\
\hline 16 & PM 179 & 0.42 & 50 & 2 \\
\hline 17 & S 23 & 0.42 & 50 & 2 \\
\hline 18 & pPGPseq-2B10 & 0.40 & 100 & 2 \\
\hline 19 & GM 1000 & 0.30 & 50 & 2 \\
\hline 20 & PM 50 & 0.08 & 50 & 2 \\
\hline 21 & GM 1864 & Monomorphic & 0 & 2 \\
\hline 22 & pPGPseq-2F05 & Monomorphic & 0 & 1 \\
\hline 23 & GM 1502 & Monomorphic & 0 & 1 \\
\hline 24 & GM 2084 & Monomorphic & 0 & 1 \\
\hline 25 & GM 2348 & Monomorphic & 0 & 1 \\
\hline 26 & S 03 & Monomorphic & 0 & 1 \\
\hline 27 & S 83 & Monomorphic & 0 & 1 \\
\hline 28 & S 21 & Monomorphic & 0 & 1 \\
\hline 29 & S 70 & Monomorphic & 0 & 1 \\
\hline \multirow[t]{2}{*}{30} & pPGSseq19D9 & Monomorphic & 0 & 1 \\
\hline & Average & 0.57 & 74.32 & 3.15 \\
\hline
\end{tabular}




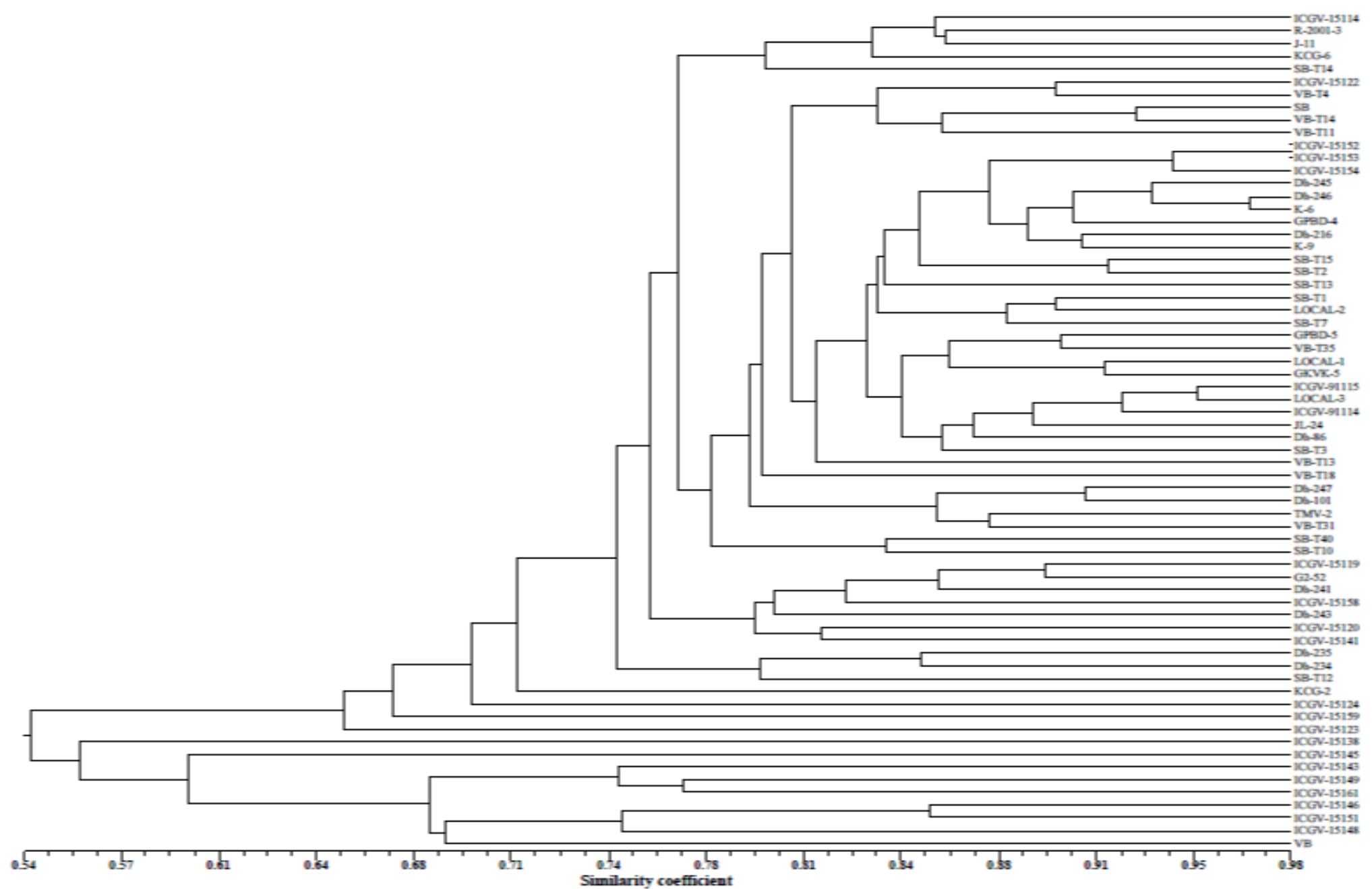

Figure.1 Genetic diversity among 66 groundnut genotypes generated using the unweighted pair group method with arithmetic mean (UPGMA) procedure based on the Jaccard's similarity coefficient created with NTSYSpc v. 2.2 
In a study with 31 groundnut genotypes that exhibited different levels of resistance to bacterial wilt, Jiang et al., (2007) also found that 29 of the 78 SSR primers were polymorphic, and amplified a total of 91 polymorphic loci with an average of 2.25 alleles per marker. Similarly, Tang et al., (2007) employed 34 SSR markers to determine the genetic diversity in four sets of 24 accessions from the four botanical varieties of cultivated groundnut, and found that 16 primers were polymorphic. This led to the conclusion that abundant inter-variety SSR polymorphism exists in groundnut.

The PIC values obtained in the present study have ranged from 0.08 for marker PM-50 to 0.83 for GM-1986, yielding a mean PIC value of 0.57.These results are in accordance with Frimpong et al., (2015). Totally 74 bands were amplified, of which 55 were polymorphic yielding mean percent polymorphism of $74.32 \%$. These results are in accordance with the study conducted by Shoba et al., (2010) wherein they assessed the diversity of 11 groundnut genotypes using 17 SSR markers, recorded $24 \%$ polymorphism. Mondal and Badigannavar (2010) similarly used 26 SSR primers to amplify 136 bands and showed that $76.5 \%$ were polymorphism in 20 cultivated groundnut genotypes that differed in resistance to rust and late leaf spot disease.

Marker GM1911 (PIC=0.71) in this study, was reported to be linked with drought tolerance QTL (Ravi et al., 2011; Gautami et al., 2012), while markers GM1577 $(\mathrm{PIC}=0.75)$ and GM1991 (PIC=0.77) were reported to be linked with the QTLs governing tolerance to late leaf spot disease (Sujay et al., 2012) and these results are in accordance with Frimpong et al., (2015).

The identification of polymorphism associated with these important traits, indicates the existence of variation for the traits at molecular level in the groundnut genotypes used in the present investigation, and they can be used in QTL mapping, and/or marker-assisted breeding activities (for example, marker-assisted backcrossing and marker-assisted recurrent selection) in groundnut.

Taken together, the results of this study demonstrate that SSR markers can be very effective in discerning variations among the 66 different groundnut genotypes despite their close relatedness, a finding consistent with other studies (Cuc et al., 2008; Carvalho et al., 2010). The mean PIC value of 0.57 suggests that the primers were highly polymorphic (Pandey et al., 2012) and can be applied to different groundnut populations in breeding programs and these findings are in confirmation with those obtained by Frimpong et al., (2015).

The cluster analysis showed similarity of 38 per cent between genotypes Dh-101 and ICGV-15143 making them as highly diverse among present genotypes. This can be explained by their origin itself, ICGV-15143 is a germplasm accession whereas Dh-101 is an improved cultivar. Most of the solitary clusters (9) are ICGV lines except KCG-2 and VB, which can also be explained by their origin as all the ICGV lines are germplasm accessions.

\section{References}

Carvalho, M. A., Quesenberry, K. H., and Gallo, M. (2010), Comparative assessment of variation in the USA Arachis pintoi (Krap. and Greg.) germplasm collection using RAPD profiling and tissue culture regeneration ability. Plant Syst. Evol. 288: 245-251.

Cuc, L. M., Mace, E. S., Crouch, J. H., Quang, V. D., Long, T. D., and 
Varshney, R. K. (2008), Isolation and characterization of novel microsatellite markers and their application for diversity assessment in cultivated groundnut (Arachis hypogaea L.). BMC Plant Biol. 8: 55.

Dwivedi, S. L., Gurtu, S., Charndra, S., Yuejin, W. and Nigam, S. N., 2001, Assessment of genetic diversity among selected groundnut germplasm RAPD Analysis. Plant Breeding., 120: 345-349

Frimpong, R. O., Sriswathi, M., Ntare, B. R. and Dakora, F. D., 2015, Assessing the genetic diversity of 48 groundnut (Arachis hypogaea L.) genotypes in the Guinea savanna agro-ecology of Ghana, using microsatellite-based markers. African J. of Biotch., 14(32): 24842493.

Gautami, B., Pandey, M. K., Vadez, V., Nigam, S. N., Ratnakumar, P., Krishnamurthy, L., Radhakrishnan, T., Gowda, M. V. C., Narasu, M. L., Hoisington, D. A., Knapp, S. J., and Varshney, R. K. (2012), Quantitative trait locus analysis and construction of consensus genetic map for drought tolerance traits based on three recombinant inbred line populations in cultivated groundnut (Arachis hypogaea L.). Mol. Breed. 30: 757-772.

Gepts, P., 1993, The use of molecular and biochemical markers in crop evolution studies. In: Evolution Any Biology, Volume 27 (Ed. Hecht), Plenum Press, New York.

Hostington, D. M., 1997, laboratory protocol (CIMMYT) Applied molecular Genetics laboratory $3^{\text {rd }}$ edition (CIMMYT) Batur Mexico D E CTI.

Jiang, H., Liao, B., Ren, X., Lei, Y., Mace, E. S., FU, T., and Crouch, J. H. (2007), Comparative assessment of genetic diversity of peanut (Arachis hypogaea L.) genotypes with various levels of resistance to bacterial wilt through SSR and AFLP analyses. J. Genet. Genomics 34: 544-554.

Mace, E. S., Phong, D. T., Upadhyaya, H. D., Chandra, S., and Crouch, J. H., 2006, SSR analysis of cultivated groundnut (Arachis hypogaea L.) germplasm resistant to rust and late leaf spot diseases. Euphytica., 152: 317-330.

Mondal, S., and Badigannavar, A. M., 2010, Molecular diversity and association of SSR markers to rust and late leaf spot resistance in cultivated groundnut (Arachis hypogaea L.). Plant Breed., 129: 68-71.

Pandey, M. K., Monyo, E., Ozias-Akins, P., Liang, X., Guimaraes, P., Nigam, S. N., Upadhyaya, H. D., Janila, P., Zhang, X., Guo, B., Cook, D. R., Bertioli, D. J., Michelmore, R., and Varshney, R. K. (2012), Advances in Arachis genomics for peanut improvement. Biotechnol. $A d v$. 30: 639-651.

Raina, S. N., Rani, V., Kojima, T., Ogihara, Y., Singh, K. P., Devrmath, R. M., 2001, RAPD and ISSR finger prints an useful genetic markers for analysis of genetic diversity, varietal identification and phylogenetic relationships in peanut (Arachis hypogaea L.) cultivar and wild species. Genome., 44: 763-772.

Ravi, K., Vadez, V., Isobe, S., Mir, R. R., Guo, Y., Nigam, S. N., Gowda, M. V. C., Radhakrishnan, T., Bertioli, D. J., Knapp, S. J., AND Varshney, R. K. (2011), Identification of several small main-effect QTLs and a large number of epistatic QTLs for drought tolerance related traits in groundnut (Arachis hypogaea L.). Theor. Appl. Genet. 122: 1119-1132.

Rohlf, F. J., 1998, NTSYSPC numerical taxonomy and multivarietal analysis, Version 2. 0. Applied Biostatics, New York.

Shoba, D., Manivannan, N., and Vindhiyavarman, P. (2010), Genetic 
diversity analysis of groundnut genotypes using SSR markers. Electron. J. Plant Breed. 1: 1420-1425.

Sohaib, R., Bibi, S., Arshad, I., Muhammad, S., Izhar, M., Muhammad, A., Zia., Muhammad, Z. A., Farooq, R., Abdul, G, and Nabila, T, 2014, SSR based genetic diversity analysis in a diverse germplasm of groundnut (Arachis hypogaea L.) from Pakistan. Australian J Crop Sci., 8(1): 55-61.

Subrahmanyam, P., Gurtu, S., Nageswara Rao, R. C. and Nigam, S. N., 2000, Identification of DNA polymorphism in cultivated groundnut using random amplified polymorphism DNA (RAPD) assay. Genome., 43: 656-660.

Sujay, V., Gowda, M. V. C., Pandey, M. K., Bhat, R. S., Khedikar, Y. P., Nadaf, H. L., Gautami, B., Sarvamangala, C., Lingaraju, S., Radhakrishnan, T., Knapp, S. J., and Varshney, R. K.
(2012), Quantitative trait locus analysis and construction of consensus genetic map for foliar disease resistance based on two recombinant inbred line populations in cultivated groundnut (Arachis hypogaea L.). Mol. Breed. 30: 773-788.

Tang, R., Gao, G., He, L., Han, Z., Shan, S., Zhong, R., ZHOU, C., JIANG, J., LI, Y., AND ZHUANG, W. (2007), Genetic diversity in cultivated groundnut based on SSR markers. J. Genet. Genomics. 34: 449-459.

Xiaoping Ren., Huifang Jiang., Zhongyuan Yan., Yuning Chen., Xiaojing Zhou., LI Huang., Yong Lei., Jiaquan HUANG., Liying Yan., Yue Qi., Wenhui Wei and Boshou LIAO, 2014, Genetic Diversity and Population Structure of the Major Peanut (Arachis hypogaea L.) Cultivars Grown in China by SSR Markers. PLoS ONE., 9(2): e88091.

\section{How to cite this article:}

Hasanali Nadaf, G. Chandrashekhara, B.N. Harish Babu and Savithramma, D.L. 2019. Assessing the Molecular Diversity in Groundnut (Arachis hypogaea L.) Genotypes Using Microsatellite-Based Markers. Int.J.Curr.Microbiol.App.Sci. 8(09): 983-993. doi: https://doi.org/10.20546/ijcmas.2019.809.116 